\title{
A visão de corpo na perspectiva de graduandos em Educação Física: fragmentada ou integrada?
}

\author{
Alan Camargo Silva* \\ Sílvia Maria Agatti Lüdorf** \\ Fernanda Azevedo Gomes da Silva*** \\ Alexandre Palma de Oliveira****
}

\begin{abstract}
Resumo: Os objetivos dessa pesquisa foram: conhecer e comparar a visão de corpo dos graduandos em Educação Física de primeiro e últimos períodos; investigar de que forma relacionam o corpo à Educação Física e à prática profissional. Os procedimentos metodológicos envolveram a aplicação de questionários a 103 alunos de um curso de graduação em Educação Física, bem como análise documental. Os resultados revelaram a predominância de uma visão técnico-biológica e fragmentada de corpo no primeiro período e, nos últimos, uma compreensão mais integrada de corpo. A forma de atuação profissional estaria ligada à orientação, nas perspectivas de saúde, estética e técnica.
\end{abstract}

Palavras-chave: Corpo. Educação Física. Formação de professores.

\section{INTRODUÇÃO}

Ao discutir as representações sobre corpo no âmbito da Educação Física, traça-se uma difícil tarefa, uma vez que a construção da área é complexa e caracterizada por diversos discursos e práticas relacionados à cultura corporal. (BRACHT, 1999; SOARES et al., 1992; RESENDE; SOARES, 1996; SOARES, 2004)

* Mestrando em Educação Física (EEFD/UFRJ). Membro do NESPEFE. Escola de Educação Física. Universidade Federal do Rio de Janeiro. Rio de Janeiro, RJ.Brasil E-mail: alancamargo10@gmail.com.

** Doutora em Educação. Professora Adjunta da Escola de Educação Física. Universidade Federal do Rio de Janeiro.Coordenadora do Núcleo de Estudos Sociocorporais e Pedagógicos em Educação Física e Esportes. Rio de Janeiro, RJ.Brasil. E-mail: sagatti@ufrj.br

*** Licenciada em Educação Física. Membro do NESPEFE. Escola de Educação Física. Universidade Federal do Rio de Janeiro. Rio de Janeiro, RJ.Brasil. E-mail: fernanda.efd@gmail.com **** Doutor em Saúde Coletiva. Professor Adjunto da Escola de Educação Física. Universidade Federal do Rio de Janeiro. Rio de Janeiro, RJ.Brasil .E-mail: palma_alexandre@yahoo.com.br 


\section{Artigor Orifinais Alan Camargo Silva et al.}

Prováveis discrepâncias vinculadas ao entendimento do que signifique corpo para aqueles que atuam na/com a Educação Física provêm, principalmente, da premissa de que tal fato seja resultante de distintos momentos socioeconômicos e políticos. Ainda que seja possível, através de autores clássicos, verificar certos discursos associados ao corpo, é válido destacar que não ocorreu (nem ocorre), de forma linear, um discurso substituindo o outro, mas sim, uma coexistência dinâmica de concepções de corpo. Para Daolio (1998) este aspecto foi positivo, uma vez que ampliou os campos de ação e reflexão referentes às questões relacionadas ao corpo na Educação Física.

Parte-se do princípio, então, de que os discursos e práticas relacionados à cultura corporal dos atores envolvidos com a Educação Física, como o de graduandos, foco deste estudo, são, em parte, reflexos do passado e da historiografia, ou seja, da forma crítica de se estudar e interpretar a história da área (FERREIRA, 2004). Exemplarmente, Daolio (1995), ao pesquisar as representações de professores de Educação Física escolar sobre corpo, verificou que a prática pedagógica voltada quase que exclusivamente à aptidão física decorre de uma compreensão biológica do corpo, ou seja, como se fosse anterior à cultura. Já no âmbito de professores universitários de Educação Física, Lüdorf (2003) identificou também sinais da compreensão do corpo em seu aspecto predominantemente técnico ou biológico, convivendo com indícios de uma concepção de corpo de cunho cultural.

Oliveira e Vaz (2004) consideram importante que teoria e história se unam, para possibilitar o exercício permanente da crítica. Consequentemente, parece ser fundamental questionar e repensar criticamente as concepções de corpo presentes na área. Desse modo, esta pesquisa tem por objetivos conhecer, analisar e comparar a visão de corpo dos graduandos em Educação Física de primeiro e últimos períodos de uma universidade pública e investigar de que forma esses relacionam o corpo à prática profissional.

A discussão sobre as questões relacionadas ao corpo e à Educação Física propiciará analisar se há modificações de como o graduando concebe o corpo durante o processo de formação acadêmica, assim como se o avanço teórico da área repercute em sua formação

Movimento, Porto Alegre, v. 15, n. 03, p. 109-126, julho/setembro de 2009. 
e como consequência, supostamente, no modo como concebe a prática pedagógica. Além disso, o presente estudo pretende auxiliar no estímulo à reflexão docente quanto à sua prática atual. É fundamental analisar se o professor de Educação Física está conectado à realidade social, conforme preconizado por Daolio (1995).

\section{ApontAmentos teóricos}

A Educação Física, ao longo de sua história, foi marcada por significativas influências, algumas das quais aqui ressaltadas. A influência médico-higienista, conforme Soares (2004), foi marcante no século XIX e início ${ }^{1}$ do século XX. A Educação Física seria a síntese perfeita da educação e da saúde, contribuindo para forjar o indivíduo produtivo, robusto e saudável, necessário à formação da sociedade brasileira (BRACHT, 1999).

A aproximação da Educação Física ao militarismo que, para Ghiraldelli Jr. (1992), teve seu auge entre 1930 e 1945, teria contribuído para a construção de corpos disciplinados e fortes, com o intuito de adequá-los ao processo produtivo ou a uma política nacionalista, decorrente da Ditadura da época, perspectiva essa referendada pelo pensamento médico-científico do corpo (BRACHT, 1999).

Outra significativa influência no contexto da Educação Física é a Competitivista ou Esportivista, principalmente após 1964 (GHIRALDELLI JR., 1992), o que leva o esporte a se firmar como elemento predominante da cultura corporal (SOARES et al., 1992). Daolio (1995), exemplarmente, verificou que os professores utilizavam-se primordialmente de técnicas esportivas ao atuarem sobre os corpos de seus alunos. Essa visão de Educação Física voltada à técnica e ao desempenho, de acordo com Bracht (1999), servia para promover uma política do corpo baseada na capacidade de trabalho e de rendimento individual e social.

Na década de 80 e, mais acentuadamente, na de 90, a Educação Física passa a incorporar uma série de discursos das áreas humanas

${ }^{1}$ Ghiraldelli Jr. (1992), didaticamente, considera a tendência Higienista até 1930.

Movimento, Porto Alegre, v. 15, n. 03, p. 109-126, julho/setembro de 2009. 


\section{Artigor Originais}

Alan Camargo Silva et al.

e sociais potencializando a abertura de uma postura mais crítica, ou progressista, sobre o corpo e a própria Educação Física. Conforme Soares et al. (1992), tal fenômeno renovador é iniciado com a visão psicomotricista, que utilizava o movimento como meio de formação.

Cabe ainda ressaltar a vinculação da Educação Física ao fenômeno do culto ao corpo, principalmente por meio da popularização das academias de ginástica e das atividades de fitness em finais dos anos 80 (NOVAES, 2001). Para Darido e Rangel (2005), a preocupação com o corpo "saudável", evocada atualmente, possui pressupostos e finalidades semelhantes ao modelo biológico higienista, com caráter renovado. Assim, o trabalho do corpo nas perspectivas de saúde, estética ou qualidade de vida, hegemonicamente baseadas nas ciências biológicas, vem a se constituir em outra significativa marca no contexto da Educação Física, tendo sido frequentemente utilizadas como argumentos para justificar sua intervenção.

Essas influências, brevemente apontadas, dentre outras, moldam as concepções de corpo e de Educação Física na contemporaneidade e podem auxiliar na interpretação dos achados empíricos da presente pesquisa, como será visto a seguir.

\section{Aspectos METOdolóGICOS}

A presente investigação está fundamentada em algumas características da pesquisa qualitativa, como buscar a compreensão de uma realidade específica e possuir um caráter interpretativo, sem, contudo, ter a pretensão de ser considerada exclusiva ou classicamente como tal. Para Alves-Mazzotti e Gewandsznajder (1999), a pesquisa pode se situar em um continuum qualitativo, sendo importante a coerência no que se refere ao problema focalizado, à metodologia utilizada e ao quadro teórico.

Denzin e Lincoln (1994) sustentam que a combinação de métodos, com vistas a melhor analisar e compreender o fenômeno, é uma estratégia que imprime rigor, amplitude e profundidade à investigação. Diante dos objetivos dessa pesquisa, optou-se pela utilização de um

Movimento, Porto Alegre, v. 15, n. 03, p. 109-126, julho/setembro de 2009. 
questionário como principal técnica, aliado à análise documental, especialmente da grade curricular e dos programas ${ }^{2}$ das disciplinas.

O questionário foi utilizado por possibilitar maior número de respondentes, além de, conforme Goldenberg (1998) deixá-los mais livres para exprimirem suas opiniões. O roteiro foi elaborado com seis questões ${ }^{3}$ abertas, de modo a privilegiar informações espontâneas, bem como, posteriormente, o caráter interpretativo da análise. $\mathrm{O}$ instrumento foi previamente validado por especialistas, tendo sido realizada uma pesquisa-piloto para verificar o alinhamento das questões aos propósitos do estudo, conforme preconiza Janesick (1994).

Procedeu-se, então, à coleta dos dados, através da aplicação do questionário a 103 graduandos, no início do semestre de 2007, sendo 56 de primeiro ${ }^{4}$ e 47 de últimos períodos, ${ }^{5}$ de um curso de Licenciatura em Educação Física de uma universidade pública do Rio de Janeiro. Os questionários foram entregues em sala de aula, após prévia autorização do(s) professor(es) de cada turma e foram respondidos simultaneamente pelos alunos, sem que mantivessem contato uns com os outros, na presença dos pesquisadores. Somente responderam aos questionários aqueles que consentiram em participar da pesquisa, conforme as diretrizes éticas para esse tipo de estudo.

Os dados foram analisados com base na análise de conteúdo, visando identificar categorias emergentes. Tal análise não é um processo meramente mecânico, mas subjetivo, uma vez que depende dos conhecimentos teóricos e da óptica do(s) pesquisador(es) (GASKELL,

\footnotetext{
${ }^{2}$ Os programas das disciplinas continham dados como ementa, objetivos, conteúdo, metodologia avaliação e bibliografia.

${ }^{3}$ As questões eram: 1) Ao mencionar "corpo", quais as seis primeiras palavras que vêm espontaneamente à sua mente? 2) O que é corpo para você? 3) De que maneira a Educação Física lida com o corpo? 4) Qual deveria ser a maior preocupação do professor de Educação Física ao trabalhar com seus alunos? 5) Você acha que o professor de Educação Física interfere na visão que os alunos têm ou deveriam ter do corpo? De que maneira? 6) Que aspectos você mais valoriza em relação ao seu próprio corpo? Você acha que este aspecto contribuirá para sua vida profissional ligada à Educação Física? Por quê?

${ }^{4} \mathrm{~A}$ aplicação do questionário no início do período foi intencional, particularmente no que se refere aos alunos de primeiro período, uma vez que se esperava captar suas opiniões ainda sem a interferência das disciplinas ministradas.

${ }^{5}$ Trabalhou-se com alunos de últimos períodos, pois, embora teoricamente o último período seja o oitavo, há alunos que demoram mais ou menos tempo para terminar a graduação.
}

Movimento, Porto Alegre, v. 15, n. 03, p. 109-126, julho/setembro de 2009. 


\section{Astifor Originair}

Alan Camargo Silva et al.

2003). As respostas foram, em um primeiro momento, agrupadas em torno de temáticas mais amplas a partir dos critérios de repetição e de relevância (TURATO, 2003). As categorias não foram definidas $a$ priori, ao contrário, foram criadas a partir dos significados que eram atribuídos, nesse caso, ao corpo, à Educação Física e à forma de interferência do professor. A seguir, foi realizada a interpretação desses significados à luz do referencial teórico utilizado. Para Alves-Mazzotti e Gewandsznajder (1999), a adoção de um esquema conceitual anteriormente à coleta de dados é útil e não impede que outras categorias teóricas sejam geradas a partir dos dados. Neste processo de análise, as categorias foram refinadas e, muitas vezes, renomeadas, até que se chegasse ao resultado "final".

Conjuntamente à análise dos dados advindos dos questionários, foi efetuada a análise documental, privilegiando-se as orientações de Alves-Mazzotti e Gewandsznajder (1999), que recomendam ser fundamental conhecer em que contexto os documentos utilizados foram criados e a que propósitos foram elaborados. Foi, então, realizada uma análise crítica do currículo do curso referido, bem como de programas de disciplinas, além do resgate de informações históricas da instituição, de modo a contextualizar e alicerçar a compreensão dos dados.

\section{EM BUSCA DE ACHADOS E INTERPRETAÇõES}

Em especial, foram analisadas três questões ${ }^{6}$ que subsidiam a discussão do que seria o corpo e como este se relacionaria à prática pedagógica, a partir da visão de alunos de Educação Física. Os resultados são apresentados no Quadro 1, que mostra as categorias centrais e a incidência de respostas, ${ }^{7}$ a título ilustrativo.

\footnotetext{
${ }^{6}$ As questões analisadas foram, primordialmente, as de números 2, 3 e 5, sendo que as outras foram utilizadas de modo a auxiliar na compreensão das respostas.

${ }^{7} \mathrm{~A}$ quantidade registrada entre parênteses representa o quanto cada categoria foi mencionada nas respostas dos graduandos. Note-se que, em alguns casos, uma única resposta pode apresentar mais de uma categoria.

Movimento, Porto Alegre, v. 15, n. 03, p. 109-126, julho/setembro de 2009.
} 


\begin{tabular}{|c|c|}
\hline Graduandos de Primeiro Período & Graduandos de Últimos Períodos \\
\hline \multicolumn{2}{|c|}{ Concepções de corpo } \\
\hline Corpo à parte $(31)$ & Corpo à parte (18) \\
\hline Corpo Interativo (9) & Corpo Interativo Social (13) \\
\hline Corpo Interativo Social (8) & Corpo Interativo (3) \\
\hline \multicolumn{2}{|c|}{ Como a Educação Física lida com o corpo } \\
\hline Saúde e Qualidade de vida (29) & Saúde e Qualidade de vida (9) \\
\hline $\begin{array}{l}\text { Aptidão fisica relacionada às habilidades } \\
\text { motoras (11) }\end{array}$ & $\begin{array}{c}\text { Aptidão fisica relacionada às habilidades } \\
\text { motoras (6) Corporeidade (6) }\end{array}$ \\
\hline Estética (9) & Estética (5) \\
\hline \multicolumn{2}{|c|}{$\begin{array}{c}\text { Forma de interferência dos professores de Educação Física na visão de corpo } \\
\text { de seus alunos }\end{array}$} \\
\hline Orientação (33) & Orientação (15) \\
\hline Modelo (10) & Modelo (8) \\
\hline Pedagógica (1) & Pedagógica (7) \\
\hline
\end{tabular}

Quadro 1: Análise comparativa entre graduandos de primeiro e últimos períodos de Educação Física.

Evidencia-se, a partir dos dados, que houve uma incidência predominante da concepção de corpo à parte, com trinta e uma menções dos graduandos do primeiro período. $\mathrm{O}$ corpo à parte emergiu a partir da atribuição dos seguintes significados ao corpo: "objeto que me capacita a realizar atividades", "conjunto de células e órgãos", "uma máquina que deve ser trabalhada para seu bom funcionamento", "um instrumento que precisa ser bem cuidado e preservado", ou seja, o corpo foi entendido como matéria, estrutura, veículo ou máquina. Tais achados deram margem a denominar essa categoria de corpo à parte, com base em Le Breton (2003), que utiliza o corpo alter ego (outro eu) para se referir ao corpo, considerado como simples suporte da pessoa, um objeto dissociado do homem, uma estrutura passível de ser modificada, cujas peças podem ser substituídas.

A segunda categoria mais mencionada no primeiro período foi a de corpo interativo, delineada a partir dos seguintes exemplos: "junção de ossos, articulações, órgãos e músculos, em equilíbrio com a mente", "conjunto do que somos por fora e por dentro, material e espírito", "junção perfeita entre o físico, o mental e o emocional".

Movimento, Porto Alegre, v. 15, n. 03, p. 109-126, julho/setembro de 2009. 


\section{Antigor Originais}

Alan Camargo Silva et al.

Dessa maneira, o corpo foi caracterizado como união ou integração entre as esferas física e espiritual, ou física e cognitiva. Embora fique evidenciada uma aparente união, o que levou a utilizar o termo corpo interativo, essa compreensão de corpo advém do histórico dualismo corpo-alma. Para Romero (2005, p. 37): "É a partir do dualismo corpo-alma que a civilização se faz e se impregna de divisões. Divisões essas nitidamente presentes na Educação Física de hoje."

Outra categoria que sobressaiu na análise foi nomeada corpo interativo-social, tendo sido identificada em trechos, tais como: "corpo é interferir com o meio. Um meio de interagir com a vida", "através dele você pode se expressar, realizar movimentos, habilidades", "forma de expressão na qual posso me comunicar com outras pessoas". Nesta concepção, o corpo parece ser visto como meio de interação social, sendo retratado como um meio de comunicação, de expressão e de contato direto com o mundo. Nesta categoria, notase que o corpo é compreendido como uma construção sociocultural, como defendido por Soares (1999), Daolio (2001) e Goellner (2005).

Observa-se a predominância do corpo à parte no primeiro e últimos períodos. Estes dados assemelham-se aos detectados por Hunger e Souza Neto (2002), que constataram a predominância de uma noção de corpo "fragmentado" em graduandos e especialistas de Educação Física, apesar da existência de alguns relatos na perspectiva integradora. Cabe apontar que a grade curricular do referido curso, não é diferente de outras da mesma área, continha um elevado número de disciplinas das ciências biológicas, com seus respectivos aprofundamentos (Anatomia, Fisiologia Humana, Fisiologia do Exercício, Bioquímica do Exercício, Cinesiologia, Biomecânica etc.), fato esse que contribui para que o discurso fragmentado da ciência medicalizada seja acentuado, dificultando o alcance de uma visão mais integrada de corpo (SILVA, 1998).

No entanto, nos últimos períodos, verificou-se com mais proeminência o corpo interativo-social, ainda que a concepção de corpo à parte continue em destaque. Diante dos resultados, parece ter havido uma significativa modificação no modo como os graduandos concebem o corpo: de uma matriz eminentemente técnica e/ou biológica, que

Movimento, Porto Alegre, v. 15, n. 03, p. 109-126, julho/setembro de 2009. 
significaria trabalhar uma noção de corpo, até certo ponto, fragmentada, para uma que o considera um processo histórico-cultural, conforme as aspirações de Daolio (1995) e Soares (2003). Esse resultado pode decorrer da influência das disciplinas de caráter pedagógico cursadas nos últimos períodos, tais como: Sociologia da Educação, Psicologia da Educação, Filosofia da Educação, além de Didática Especial e Prática de Ensino (estágio supervisionado).

Ao serem indagados sobre a forma como a Educação Física lida com o corpo, a categoria mais mencionada no primeiro período foi a de promoção de saúde e de qualidade de vida, citada 29 vezes, como em "trabalhando e mantendo o bom funcionamento", "tratando da saúde e bem-estar", "exercitando e prevenindo doenças", "preparando-o para ser saudável". Essa categoria se respalda em discursos tradicionais que vinculam a Educação Física à saúde, em que a prática de atividade física propicia o aprimoramento do condicionamento físico e mental, tornando o corpo mais funcional e capaz, auxiliando também na melhora da qualidade de vida.

Tal resultado, de cunho biologizante, ratifica a afirmativa de Resende e Soares (1996) de que muitos profissionais acreditam que o papel da Educação Física seja a promoção e a manutenção da saúde. A ideia arraigada de que o exercício físico conduz à saúde e qualidade de vida é predominante nos textos sobre o tema. De acordo com Warburton et al. (2006), a prática regular poderia possibilitar a prevenção primária e secundária de inúmeras doenças, além de contribuir para melhorar a qualidade de vida das pessoas. Por outro lado, alguns pesquisadores (PALMA, 2001; PALMA et al., 2003; MIRA, 2003) têm questionado a noção de causalidade entre exercícios físicos e saúde, em parte porque o próprio conceito de saúde tem sido debatido, considerando visões de mundo e perspectivas de análise diferenciadas. Compreender a saúde como ausência de doenças pode significar uma simplificação de um fenômeno por demais complexo. É preciso, também, refletir sobre os conceitos correlatos, como o de sedentarismo que, para Fraga (2006), pode suscitar contradições de tal forma que, a depender do critério utilizado, o indivíduo (ou o grupo estudado) pode ser considerado sedentário ou ativo.

Movimento, Porto Alegre, v. 15, n. 03, p. 109-126, julho/setembro de 2009. 


\section{Antigor Originais}

Alan Camargo Silva et al.

Do mesmo modo, a noção de que a prática regular de exercícios físicos conduz à melhoria da qualidade de vida carece de maiores cuidados. De uma forma geral, ao se aceitar esta condição consideram-se os aspectos funcionais do organismo (WARBURTON et al., 2006). Contudo, qualidade de vida pode ser compreendida a partir de uma perspectiva individual, que considera aspectos históricos, culturais, sociais e econômicos, ou ainda, de uma perspectiva coletiva, que diz respeito aos níveis materiais mínimos e universais como alimentação, acesso à rede de esgoto e água potável, habitação, educação, trabalho, saúde, lazer etc. (MINAYO et al., 2000).

A segunda categoria de maior destaque foi a de aptidão física relacionada às habilidades motoras, ${ }^{8}$ com 11 apontamentos, observável nos exemplos "proporcionando ao indivíduo uma maior capacidade", "através de movimentos e preparo físico", "na parte física, pois fazemos muitos exercícios". Registra-se uma exaltação da prática de movimentos e exercícios voltados ao enfoque físico e ao aprimoramento desportivo. Tal achado se assemelha ao encontrado por Jesus (2005), que identificou ser muito latente o sentido de professor-atleta e de formador de desportistas, por parte de graduandos.

Para os alunos de últimos períodos, contudo, essa tendência técnico-biológica de como a Educação Física lida com o corpo apresentou declínio. Ainda que apareça a categoria vinculada à aptidão física relacionada às habilidades motoras, surge, com igual força, a caracterizada como corporeidade, definida a partir de frases como "Ensina como interagir com o meio", "Ajuda na melhora dos movimentos, contribuindo para a melhora da expressão corporal", "A Educação Física nos fornece muitos meios de atuação do nosso corpo no ambiente. Refletimos sobre o âmbito estético, corporeidade, psicomotricidade, entre outros". Nesse contexto, nota-se ainda a

\footnotetext{
${ }^{8}$ Ainda que a aptidão física possa estar relacionada à saúde a partir da melhoria da condição aeróbia, dos níveis de força, de resistência muscular, da composição corporal e da flexibilidade (visão biológica da saúde), Caspersen et al. (1985) também consideram que a aptidão física pode estar associada a uma série de atributos que as pessoas deveriam possuir para desempenhar determinadas tarefas motoras ou habilidades atléticas.

Movimento, Porto Alegre, v. 15, n. 03, p. 109-126, julho/setembro de 2009.
} 
disputa entre o corpo visto como dissociado do indivíduo, caracterizado como um instrumento para a performance (ter um corpo), e o Homem ser um corpo (SANTIN, 2001).

Aqui parece haver outro indicativo de alteração na maneira como os acadêmicos compreendem o corpo, provavelmente decorrente do processo de formação. $\mathrm{O}$ fato da perspectiva técnico-biológica ter esvaecido, ao mesmo tempo em que surge a da corporeidade, pode estar relacionado ao conhecimento teórico decorrente das disciplinas cursadas. Observou-se, na grade curricular, que os alunos dessa graduação, em específico, poderiam optar por dois aprofundamentos, Desporto ou Recreação e Lazer. A análise dos programas das disciplinas demonstrou que, embora as obrigatórias relativas ao primeiro aprofundamento guardassem um caráter essencialmente técnico (Ex.: Basquetebol, Futebol, Tênis, Judô, Ginástica Artística etc), por se tratar de um curso de Licenciatura, os alunos dispunham de disciplinas ligadas a essa especificidade, tais como Sociologia da Educação, Psicologia da Educação, Didática em Educação Física, dentre outras. Além disso, na grade curricular, constam disciplinas ligadas à Educação Física Escolar como Teoria e Prática da Ginástica Escolar, Avaliação em Educação Física Escolar e Psicomotricidade. Uma análise mais detida da bibliografia recomendada nos programas demonstrou a presença de conteúdos específicos da escola, tais como as principais tendências pedagógicas, além de aproximações teóricas ligadas ao corpo em uma perspectiva sociocultural.

O corpo permeia, aqui e ali, as discussões empreendidas nessas e em outras disciplinas, bem como dá nome a algumas: Introdução ao Estudo da Corporeidade, Estudo dos Parâmetros do Corpo e Antropologia do Corpo. A análise do currículo da instituição demonstra, portanto, que há uma significativa influência de discursos, que não apenas os técnico-biológicos, na formação dos acadêmicos estudados, o que parece ter influenciado na percepção que os de últimos períodos possuem sobre o corpo.

Esse fato, até onde se pode verificar, parece ser particularidade da instituição pesquisada, uma vez que Hunger e Souza Neto (2002) detectaram que, nos cursos de graduação em Educação Física, além

Movimento, Porto Alegre, v. 15, n. 03, p. 109-126, julho/setembro de 2009. 


\section{Artigor Originais}

Alan Camargo Silva et al.

da fragmentação das disciplinas acadêmicas e falta de aplicabilidade na atuação profissional, sempre se evidenciou a construção de um arcabouço conceitual de conhecimentos sobre corpo com preponderância das ciências biológicas, conclusão essa endossada por Daolio (2001).

Ao serem indagados quanto à interferência do professor de Educação Física na visão de corpo de seus alunos, houve unanimidade em confirmar que há interferência, primordialmente na perspectiva de orientação, categoria representante de frases, tais como: "pois conscientiza que cada pessoa tem o seu máximo, ou seja, seu limite", "dando exemplos, tipo, se o professor manda correr, corre junto", "o professor deve saber passar para o aluno a ideia de que corpo é uma máquina, e que precisa de cuidados para trabalhar sempre em alto nível", "mostrando os limites necessários para o seu bom funcionamento". Evidenciou-se, a partir desses exemplos, uma preocupação dos graduandos em intervir eminentemente através da transmissão de informações técnicas e de caráter funcional, relativas à saúde, estética ou ao aprimoramento técnico-desportivo, sem a pretensão de gerar reflexões críticas. Nota-se, nessa visão, um reducionismo no papel atribuído ao professor de Educação Física, que é visto como transmissor de informações ao aluno. Para Paulo Freire (2004, p. 37): “[...] transformar a experiência educativa em puro treinamento técnico é amesquinhar o que há de fundamentalmente humano no exercício educativo: o seu caráter formador."

Percebe-se que os resultados possuem consonância com o que Daolio salienta: "Ao trabalhar diretamente com o corpo dos alunos, o professor interfere na concepção e na representação que os alunos têm do próprio corpo. Interfere, por extensão, na própria cultura que dá suporte a essas representações.” (DAOLIO, 1995, p. 96)

Em menor grau para ambos os períodos, emerge como a segunda categoria mais mencionada, a de modelo, a qual é caracterizada na forma de interferência do professor de Educação Física, como "de acordo com o que ele ensina, valoriza e prioriza", "pela maneira como pensa, se expressa, se comporta", "na forma física apresentada pelo professor que muitas vezes deve ser exemplo para

Movimento, Porto Alegre, v. 15, n. 03, p. 109-126, julho/setembro de 2009. 
o aluno". Tal categoria é constituída a partir da importância atribuída à aparência, às crenças, aos hábitos e às diversas atitudes do professor. Parece transparecer, nesse caso, certa exigência que a sociedade exalta com relação aos modelos de corpo e de saúde, que se refletem no profissional de Educação Física que trabalha diretamente com o corpo (LÜDORF, 2004). Para Freire et al. (2002), uma imagem estereotipada e a habilidade física parecem credenciais para uma intervenção profissional competente.

Em especial, nos graduandos de últimos períodos a categoria pedagógica apareceu consideravelmente em frases como "estimulando essas sensações corporais e emotivas através de atividades físicas", "proporcionando relações do corpo com materiais, com outros corpos e com o ambiente", "ele pode interferir desenvolvendo atividades que desafiem a motricidade dos alunos, que estimulem movimentos novos no aprendizado das crianças”. Indo ao encontro dos dados apresentados até o momento, há indicativos de que os conteúdos de cunho pedagógico trabalhados na graduação, essencialmente nas disciplinas cursadas nos últimos períodos, tenham exercido significativa influência no modo como a Educação Física interfere na visão de corpo do aluno. Entretanto, o aspecto pedagógico parece estar mais atrelado a uma compreensão de corpo de natureza psicomotora, o que fica patente ao se analisar as indicações bibliográficas que constam nos programas ${ }^{9}$ dessas disciplinas.

Se a relevância alcançada pela categoria pedagógica é digna de nota, pode ser considerado até certo ponto surpreendente o fato de não ter sido mencionada a educação na perspectiva de formação humana, tal como apregoam as tendências renovadoras da Educação Física brasileira. Esse dado pode representar que, embora as tendências pedagógicas venham sendo amplamente discutidas no âmbito teórico, ainda a aplicação prática ou a sua disseminação nos cursos de formação de professores é lenta e atinge uma parcela de professores e alunos ainda modestamente.

${ }^{9}$ Os autores mais utilizados são: Aucouturier, Ajuriaguerra, Dupré, Le Boulch, além de outros, como Vigotsky, Piaget, Wallon e o próprio João Batista Freire.

Movimento, Porto Alegre, v. 15, n. 03, p. 109-126, julho/setembro de 2009. 


\section{Antigor Originais}

Alan Camargo Silva et al.

\section{CONSIDERAÇõES FINAIS}

Na realidade estudada, foram identificadas diferenças entre as concepções de corpo de graduandos de primeiro e de últimos períodos. Inicialmente, houve a predominância de uma visão de corpo fragmentado, cuja hegemonia começou a ser quebrada a partir da concepção de uma visão de corpo mais integrado. Esta modificação na concepção de corpo se mostrou presente também ao serem indagados sobre a forma de atuação do professor de Educação Física. Além do tradicional discurso de caráter biologizante, as respostas de alunos de últimos períodos passaram a contemplar o viés da corporeidade.

Detectou-se, também, haver consenso entre os graduandos, de que o professor de Educação Física interfere na visão de corpo dos seus alunos, basicamente através da orientação sobre questões associadas à saúde, à estética e à técnica. Observou-se, contudo, que nos últimos períodos, o aspecto pedagógico passou a ser mais significativamente contemplado.

Conclui-se que os acadêmicos do curso pesquisado apresentaram uma visão de corpo ainda marcada por uma tendência biologizante, como não poderia deixar de ser, dada a construção histórica da Educação Física, no entanto, surgiram importantes indícios de modificação ou ampliação dessa concepção, devido, possivelmente, sem exaurir outros fatores complexos e interligados, ao arcabouço teórico derivado das disciplinas do curso de Licenciatura ora pesquisado.

Movimento, Porto Alegre, v. 15, n. 03, p. 109-126, julho/setembro de 2009. 
The body on the vision of undergraduate Physical Education students: fragmentized or integrated? Abstract: The purposes of this research are to study and compare the conceptions of body of undergraduate students of first and last semesters of a Physical Education graduation course, as well as to investigate how they relate the body with professional practice. The data were collected by a questionnaire, applied in 103 students of Physical Education, and by documental analyses. Results indicate a predominance of technical conception of the body in the first period and an integrated view in the last period. The professional practice is conceived toward an orientation perspective, based on health, aesthetic and technical guidelines.

Keywords: Body. Physical Education. Teachers training.

El cuerpo en la visión de estudiantes de Educación Física: fragmentada o integrada?

Resumen: Los objetivos de esta pesquisa son investigar y comparar la visión de cuerpo de estudiantes de primero y último semestres de Educación Física, ademas investigar como relacionan el cuerpo a la práctica profesional. Para la colecta de datos, fué utilizado un cuestionario aplicado a 103 estudiantes de Educación Física y analice documental. Los resultados revelan predominancia de una visión técnica y fragmentada del cuerpo en el primer período y una compreensión integrada en el último período. La forma de la atuación profesional estaria conetada con la orientación, sobretodo en las perspectivas de salud, estética y técnica. Palabras clave: Cuerpo. Educacion Física. Formacion de professores.

\section{REFERÊNCIAS}

ALVES-MAZZOTTI, A. J.; GEWANDSZNAJDER, F. O método nas ciências naturais e sociais: pesquisa quantitativa e qualitativa. 2.ed., São Paulo: Pioneira, 1999.

BRACHT, V. A constituição das teorias pedagógicas da educação física. Caderno Cedes, Campinas, SP, v. 19, n. 48, p. 69-88, ago. 1999.

CASPERSEN, C.J.; POWELL, K.E.; CHRISTENSON, G.M. Physical Activity, Exercise, and Physical Fitness: Definitions and Distinctions for Health-Related Research. Public Health Reports, Washington, v. 100, n. 2, p. 126-31, 1985.

DAOLIO, J. Da cultura do corpo. 6. ed. Campinas: Papirus, 1995.

Movimento, Porto Alegre, v. 15, n. 03, p. 109-126, julho/setembro de 2009. 


\section{Antigor Originais}

Alan Camargo Silva et al.

DAOLIO, J. Educação física brasileira: autores e atores da década de 1980 Campinas, SP: Papirus, 1998.

DAOLIO, J. A antropologia social e a educação física: possibilidades de encontro In: CARVALHO, Y. M.; RUBIO, K. (Orgs.) Educação Física e Ciências Humanas. São Paulo: Hucitec, 2001, p. 27-38.

DARIDO, S. C.; RANGEL, I. C. A. Educação física na escola: implicações para prática pedagógica. Rio de Janeiro: Guanabara Koogan, 2005.

DENZIN, N. K.; LINCOLN, Y. S. Entering the field of qualitative research. In: DENZIN N. K.; LINCOLN, Y. S. (Ed.). Handbook of qualitative research. London: Sage, 1994, p. 1-17.

FRAGA, A.B. Promoção da vida ativa: nova ordem físico-sanitária na educação dos corpos contemporâneos. In: BAGRICHEVSKY, M.; PALMA, A.; ESTEVÃO, A.; DA ROS, M. (Org.). A saúde em debate na educação física. Blumenau: Edibes, 2006 , v. 2. p. $105-18$

FERREIRA, A. B. H. Novo dicionário Aurélio: dicionário eletrônico. Versão 5.0 rev. atual. Curitiba: Positivo Informática, 2004, CD-Rom.

FREIRE, E. S.; VERENGUER, R. C. G.; REIS, M. C. C. Educação Física: pensando a profissão e a preparação profissional. Revista Mackenzie de Educação Física e Esporte, São Paulo, v. 1, n.1, p. 39-46, jan./dez. 2002.

FREIRE, P. Pedagogia da autonomia: saberes necessários à prática educativa 30. ed. São Paulo: Paz e Terra, 2004.

GASKELL, G. Entrevistas individuais e grupais. In: BAUER, M. W.; GASKEL, G. (Ed.). Pesquisa qualitativa com texto, imagem e som: um manual prático. 2. ed. Tradução de Pedrinho A. Guareschi. Petrópolis, RJ: Vozes,2003. p. 64-89.

GHIRALDELLI JR., P. Educação Física Progressista: a pedagogia crítico-socia dos conteúdos e a educacao física brasileira. São Paulo: Loyola, 1992.

GOELLNER, S. V. A produção Cultural do Corpo. In: Guacira Lopes Louro; Jane Felipe; Silvana Vilodre Goellner. (Org.). Corpo, Gênero e Sexualidade. 2. ed. Petrópolis: Vozes, 2005 , v. 1, p. $28-40$

GOLDENBERG, M. A arte de pesquisar: como fazer pesquisa qualitativa em Ciências Sociais. 2. ed. Rio de Janeiro: Record, 1998

HUNGER, D. A. C. F.; SOUZA NETO, S. História e currículo em educação física: corpo e "corpos" fragmentados... In: CONGRESSO BRASILEIRO DE HISTÓRIA DA EDUCAÇÃO FÍSICA, ESPORTE, LAZER E DANÇA. 8, 2002. Anais..., Ponta Grossa: UFPr, 2002, v.1. p. 35-43.

JANESICK, V. J. The dance of qualitative research design: metaphor, methodolatry and meaning. In: DENZIN, N. K.; LINCOLN, Y. S. (Ed.). Handbook of qualitative research. London: Sage, p. 209-219, 1994.

Movimento, Porto Alegre, v. 15, n. 03, p. 109-126, julho/setembro de 2009. 
JESUS, C. C. Visões das práticas e do profissional de educação física escolar. Dissertação (Mestrado). Programa de Pós-Graduação em Educação. Universidade Católica de Petrópolis, 2005.

LE BRETON, D. Adeus ao corpo: antropologia e sociedade. Campinas, SP: Papirus, 2003.

LÜDORF, S. M. A. Concepções de corpo na graduação em Educação Física: um estudo preliminar com professores. Educación Física y Deportes. Revista Digital, Buenos Aires, v. 9, n. 66, nov. 2003. Disponível em: www.efdeportes.com/ efd66/corpo.htm Acesso em 20 de agosto de 2007.

LÜDORF, S. M. A. Do corpo design à educação sociocorporal: o corpo na formação de professores de Educação Física. Tese (Doutorado). Faculdade de Educação da Universidade Federal do Rio de Janeiro, 2004.

MINAYO, M.C.S.; HARTZ, Z.M.A.; BUSS, P.M. Qualidade de vida: um debate necessário. Ciência \& Saúde Coletiva, Rio de Janeiro, v. 5, n. 1, p. 7-18, 2000.

MIRA, C.M. Exercício físico e saúde: da crítica prudente. In: BAGRICHEVSKY, M.; PALMA, A.; ESTEVÃO, A. (Orgs). A saúde em debate na educação física. Blumenau: Edibes, 2003. p. 169-91.

NOVAES, J. Estética: o corpo na academia. Rio de Janeiro: Shape, 2001.

OLIVEIRA, M. A. T.; VAZ, A. F. Educação do corpo: teoria e história. Perspectiva: Revista do Centro de Ciências da Educação, Florianópolis, v. 22, número especial, p. 13-19, jul./dez. 2004.

PALMA, A.; BAGRICHEVSKY, M.; ESTEVÃO, A. Análise sobre os limites da inferência causal no contexto investigativo sobre "exercício físico e saúde". In: BAGRICHEVSKY, M.; PALMA, A.; ESTEVÃO, A. (Orgs). A saúde em debate na educação física. Blumenau: Edibes, 2003. p. 33-51.

PALMA, A. Educação física, corpo e saúde: uma reflexão sobre outros "modos de olhar". Revista Brasileira de Ciências do esporte, Campinas, v. 22, n. 2, p. 2339, 2001.

RESENDE, H. G.; SOARES, A. J. G. Conhecimento e especificidade da educação física escolar, na perspectiva da cultura corporal. Revista Paulista de Educação Física, São Paulo, supl. 2, p. 49-59, 1996.

ROMERO, E. Do corpo docilizado na Aufklärung ao corpo generificado no século XXI. In: DANTAS, E. H. M. (Org.) Pensando o corpo e o movimento. 2. ed. Rio de Janeiro: Shape, p. 35-94, 2005.

SANTIN, S. O corpo simplesmente corpo. Movimento, Porto Alegre, v. 7, n. 15, p. $57-74,2001$.

SILVA, J. L. B. A concepção de corpo dos acadêmicos do curso de educação física da Universidade Federal de Santa Maria/RS. Kinesis, Santa Maria, n. 19, p. 85103, 1998.

Movimento, Porto Alegre, v. 15, n. 03, p. 109-126, julho/setembro de 2009. 


\section{Artigor Origimais Alan Camargo Silva et al.}

SOARES, C. L. Corpo e educação (Apresentação). Caderno CEDES, Campinas, SP, v.19, n. 48, p. 5-6, ago., 1999

SOARES, C. L. Apresentação. Pro-posições, Campinas, SP, v. 14, n. 2(41), p. 1519, mai./ago. 2003.

SOARES, C. L. Educação Física: raízes européias e Brasil. 3. ed. Campinas, SP: Autores Associados, 2004.

SOARES, C. L. et al.(org). Metodologia do ensino de educação física. São Paulo: Cortez, 1992.

TURATO, E. R. Tratado da metodologia da pesquisa clínico-qualitativa: construção teórico-epistemológica, discussão comparada e aplicação nas áreas da saúde e humanas. 2.ed. Petrópolis, RJ: Vozes, 2003.

WARBURTON, D.E.R.; NICOL, C.W.; BREDIN, S.S.D. Health benefits of physical activity: the evidence. CMAJ, Ottawa, v. 174, n. 6, p. 801-9, 2006.

Recebido em: 23.02. 2008

Aprovado em: 9.03.2009

Movimento, Porto Alegre, v. 15, n. 03, p. 109-126, julho/setembro de 2009. 